\title{
The Legendre Matrix-Collocation Approach for Some Nonlinear Differential Equations Arising in Physics and Mechanics
}

\author{
Duygu Dönmez Demir ${ }^{*}$, Tuğçe Çınardalı², Ömür Kıvanç Kürkçü³ ${ }^{3}$ Mehmet Sezer ${ }^{4}$ \\ $\mathbf{1}^{*}$ Manisa Celal Bayar University, Faculty of Art\&Sciences, Department of Mathematics, 45140, Manisa, Turkey (ORCID: 0000-0003-0886-624X) \\ 2 İzmir Turkish College, Bornova, İzmir, Turkey \\ 3 Izmir University of Economics, Department of Mathematics, İzmir, Turkey (ORCID: 0000-0002-3987-7171) \\ ${ }^{4}$ Manisa Celal Bayar University, Faculty of Art\&Sciences, Department of Mathematics, 45140, Manisa, Turkey (ORCID: 0000-0002-7744-2574)
}

(First received 3 January 2019 and in final form 2 March 2019)

(DOI: 10.31590/ejosat.507708)

REFERENCE: Demir, D. D., Çınardalı, T., Kürkçü, Ö. K. \& Sezer, M. (2019). The Legendre Matrix-Collocation Approach for Some Nonlinear Differential Equations Arising in Physics and Mechanics. European Journal of Science and Technology, (15), 289-296.

\begin{abstract}
In this study, the Legendre operational matrix method based on collocation points is introduced to solve high order ordinary differential equations with some nonlinear terms arising in physics and mechanics. This technique transforms the nonlinear differential equation into a matrix equation with unknown Legendre coefficients via mixed conditions. This solution of this matrix equation yields the Legendre coefficients of the solution function. Thus, the approximate solution is obtained in terms of Legendre polynomials. Some test problems together with residual error estimation are given to show the usefulness and applicability of the method and the numerical results are compared.
\end{abstract}

Keywords: Legendre Polynomials and Series, Nonlinear Ordinary Differential Equation, Matrix Method, Residual Error.

\section{Fizik ve Mekanikte Ortaya Çıkan Bazı Lineer Olmayan Diferansiyel Denklemler için Legendre Matris-Kollokasyon Yaklaşımı}

\begin{abstract}
Özet
Bu çalışmada, fizik ve mekanikte ortaya çıkan lineer olmayan bazı terimlere sahip yüksek mertebeden adi diferansiyel denklemlerin çözümü için, kollokasyon noktalarına dayanan operasyonel Legendere matris metodu takdim edilmiştir. Bu teknik, karışık koşullar sayesinde, bilinmeyen Legendre katsayıları ile lineer olmayan bir diferansiyel denklemi bir matris denklemine dönüştürür. Bu matris denkleminin çözümü, çözüm fonksiyonunun Legendre katsayılarını verir. Böylece, yaklaşık çözüm Legendre polinomları cinsinden elde edilir. Yöntemin faydasını ve uygulanabilirliğini göstermek için, rezidüel hata tahmini ile birlikte bazı test problemleri verilir ve nümerik sonuçlar kıyaslanır.
\end{abstract}

Anahtar Kelimeler: Legendre Polinomları ve Serisi, Lineer Olmayan Adi Diferansiyel Denklemler, Matris Metodu, Rezidüel Hata.

\footnotetext{
* Corresponding Author: Manisa Celal Bayar Üniversitesi, Fen-Edebiyat Fakültesi, Matematik Bölümü, Manisa, Türkiye, ORCID: 0000-0003-0886624X, duygu.donmez@,cbu.edu.tr
} 


\section{Introduction}

Orthogonal polynomials are extensively considered in many area of mathematics, sciences and engineering. One of these polynomials is the Legendre polynomials which are orthogonal on $[-1,1]$ with respect to the weight function $w(x)=1$. The mentioned polynomials play an important role in many branches such as mathematics, statics and other scientific (Kreyszig, 2013; El-Mikkawy et. al. 2005; Everitt et. al. 2002; Sezer and Gülsu, 2009; Gülsu et. al. 2009).

The solutions of nonlinear ordinary differential equations are frequently investigated by many researches (Yüksel et. al. 2011; Akyüz Daşcıŏlu and Çerdik Yaslan, 2011; Gürbüz and Sezer 2016). These equations are characterized by the presence of the nonlinear terms and have a great importance in explaining many different phenomena. Generally, the nonlinear differential equations have no analytical solution. Therefore, we need to numerical methods to obtain approximate solutions.

In this study, we develop a numerical method based on the matrix relations of Legendre polynomials and their derivatives by means of the matrix methods based on collocation points given by Sezer and co-workers (Sezer and Gülsu, 2009; Gülsu et. al. 2009; Yüksel et. al., 2011; Kürkçü et. al., 2017) and apply to the m-th order ordinary differential equation with first and second order nonlinear terms in the general form (Yüksel et. al., 2011; Akyüz Daşc1oğlu and Çerdik Yaslan, 2011)

$$
\sum_{k=0}^{m} F_{k}(t) y^{(k)}(t)+\sum_{p=0}^{2} \sum_{q=0}^{p} Q_{p q}(t) y^{(p)}(t) y^{(q)}(t)=g(t) ; \quad-1 \leq t \leq 1
$$

under the mixed conditions

$$
\sum_{k=0}^{m}\left(a_{k j} y^{(k)}(-1)+b_{k j} y^{(k)}(0)+c_{k j} y^{(k)}(1)\right)=\lambda_{i} ; \quad i=0,1, \ldots, m-1
$$

where $F_{k}(t), Q_{p q}(t)$ and $g(t)$ are analytic functions on interval $-1 \leq t \leq 1, a_{k j}, b_{k j}, c_{k j}$ and $\lambda_{i}$ are convenient real constants. The aim of this study is to get the solution of the problem (1)-(2) as the truncated Legendre series defined by

$$
y(t) \cong y_{N}(t)=\sum_{\mathrm{n}=0}^{N} a_{n} P_{n}(t) ; \quad-1 \leq t \leq 1
$$

where $P_{n}(t), n=0,1, \ldots, N$ denotes the Legendre polynomials given in (Kreyszig, 2013; Everitt et. al. 2002).

and $a_{n}(0 \leq n \leq N)$ are unknown Legendre coefficients $(N \geq m)$.

\section{Material and Method}

\subsection{Matrix Relations associated with Legendre Polynomials and Series}

In this section, we constitute the matrix forms of each term in Eq. (1). Firstly, we can write the approximate solution $y_{N}(t)$ defined by truncated Legendre series (3) in the matrix form

$$
y(t) \cong y_{N}(t)=\mathbf{P}(t) \mathbf{A}
$$

where $\mathbf{P}(t)=\left[\begin{array}{lll}P_{0}(t) & P_{1}(t) \ldots P_{N}(t)\end{array}\right]$ and $\mathbf{A}=\left[\begin{array}{lll}a_{0} & a_{1} \ldots & a_{N}\end{array}\right]^{T}$. Using the recurrence formulas 
$(2 n+1) P_{n}(t)=P_{n+1}^{\prime}(t)-P_{n-1}^{\prime}(t) ; n \geq 1$ where $P_{0}^{\prime}(t)=0$ and $P_{1}^{\prime}(t)=P_{0}(t)$ for $n=0,1, \ldots, N$, we have recurrence relation between the matrix $\mathbf{P}(t)$ and its derivate $\mathbf{P}^{(k)}(\boldsymbol{t})$ in the form

$\mathbf{P}^{(k)}(t)=\mathbf{P}(t) \boldsymbol{\Pi}^{\mathbf{k}} ; k=0,1, \ldots, m$

$\boldsymbol{\Pi}=\left[\begin{array}{cccccccc}0 & 1 & 0 & 1 & 0 & \cdots & 0 & 1 \\ 0 & 0 & 3 & 0 & 3 & \cdots & 3 & 0 \\ 0 & 0 & 0 & 5 & 0 & \cdots & 0 & 5 \\ 0 & 0 & 0 & 0 & 7 & \cdots & 7 & 0 \\ \vdots & \vdots & \vdots & \vdots & \vdots & \ddots & \vdots & \vdots \\ 0 & 0 & 0 & 0 & 0 & \cdots & 2 N-3 & 0 \\ 0 & 0 & 0 & 0 & 0 & \cdots & 0 & 2 N-1 \\ 0 & 0 & 0 & 0 & 0 & \cdots & 0 & 0\end{array}\right]_{(N+1) \times(N+1)}$

$\boldsymbol{\Pi}^{\mathbf{0}}=\left[\begin{array}{cccc}1 & 0 & \ldots & 0 \\ 0 & 1 & \ldots & 0 \\ \vdots & \vdots & \ddots & \vdots \\ 0 & 0 & \ldots & 1\end{array}\right]_{(N+1) \times(N+1)}$

From (3) and (5), we obtain the matrix relation as follows:

$y^{(k)}(t) \cong y_{N}{ }^{(k)}(t)=\mathbf{P}^{(k)}(t) \mathbf{A}=\mathbf{P}(t) \boldsymbol{\Pi}^{k} \mathbf{A} ; k=0,1, \ldots, m$

Using the Legendre explicit form and taking the matrix relation (6) for $n=0,1, \ldots, N$, the matrix relations in the following are obtained (Gülsu et. al., 2009; Yüksel et. al., 2011 ):

$\mathbf{P}(t)=\mathbf{X}(t) \mathbf{D} ; \quad \mathbf{P}(x)=\left[\begin{array}{llll}P_{0}(t) & P_{1}(t) & \ldots & P_{N}(t)\end{array}\right], \mathbf{X}(t)=\left[\begin{array}{llll}1 & t & \ldots & t^{N}\end{array}\right]$

$\left(y^{(0)}(t)\right)^{2}=\mathbf{P}(t) \overline{\mathbf{P}}(t) \overline{\mathbf{A}}$

$y^{(1)}(t) y^{(0)}(t)=\mathbf{P}(t) \Pi \overline{\mathbf{P}}(t) \overline{\mathbf{A}}$

$\overline{\mathbf{A}}=\left[\begin{array}{llll}a_{0} A & a_{1} A & \ldots & a_{N} A\end{array}\right]^{T}$

$\left(y^{(1)}(t)\right)^{2}=\mathbf{P}(t) \boldsymbol{\Pi} \overline{\mathbf{P}}(t) \overline{\boldsymbol{\Pi}} \overline{\mathbf{A}}$

$y^{(2)}(t) y^{(1)}(t)=\mathbf{P}(t) \boldsymbol{\Pi}^{2} \overline{\mathbf{P}}(t) \overline{\boldsymbol{\Pi}} \overline{\mathbf{A}}$

$y^{(2)}(t) y^{(0)}(t)=\mathbf{P}(t) \Pi^{2} \overline{\mathbf{P}}(t) \overline{\mathbf{A}}$

$\left(y^{(2)}(t)\right)^{2}=\mathbf{P}(t) \boldsymbol{\Pi}^{2} \overline{\mathbf{P}}(t) \overline{\boldsymbol{\Pi}}^{2} \overline{\mathbf{A}}$

$\overline{\mathbf{P}}(t)=\operatorname{diag}\left[\begin{array}{llll}P(t) & P(t) & \ldots & P(t)\end{array}\right]_{(N+1)^{2} \times(N+1)^{2}}$

$\overline{\boldsymbol{\Pi}}^{2}=\operatorname{diag}\left[\begin{array}{llll}\Pi^{2} & \Pi^{2} & \ldots & \Pi^{2}\end{array}\right]_{(N+1)^{2} \times(N+1)^{2}}$.

Here, the transient matrix D is given in (Sezer and Gülsu, 2010; Gülsu et. al., 2009). Now, we define the collocation points for interval $[-1,1]$ as

$t_{i}=-1+\frac{2}{N} i ; i=0,1, \ldots, N$

Substituting collocation points (8) into Eq. (1) and the matrix relations (7) yields

$\sum_{k=0}^{2} \mathbf{F}_{k} \mathbf{Y}^{(k)}+\sum_{p=0}^{2} \sum_{q=0}^{p} \mathbf{Q}_{p q} \mathbf{Y}^{(p, q)}=\mathbf{G}$

where $\mathbf{F}_{k}=\operatorname{diag}\left[F_{k}\left(t_{0}\right) \quad F_{k}\left(t_{1}\right) \quad \ldots \quad F_{k}\left(t_{N}\right)\right]$ and

$\mathbf{Y}^{(k)}=\left[\begin{array}{c}y^{(k)}\left(t_{0}\right) \\ y^{(k)}\left(t_{1}\right) \\ \vdots \\ y^{(k)}\left(t_{N}\right)\end{array}\right] \quad \mathbf{Y}^{(p, q)}=\left[\begin{array}{c}y^{(p)}\left(t_{0}\right) y^{(q)}\left(t_{0}\right) \\ y^{(p)}\left(t_{1}\right) y^{(q)}\left(t_{1}\right) \\ \vdots \\ y^{(p)}\left(t_{N}\right) y^{(q)}\left(t_{N}\right)\end{array}\right]$

$\mathbf{Y}=\left[\begin{array}{c}g\left(t_{0}\right) \\ g\left(t_{1}\right) \\ \vdots \\ g\left(t_{N}\right)\end{array}\right]$

Putting the collocation points (8) into the matrix relations (6) and (7), we have the system in the following

$y^{(k)}\left(t_{i}\right) \cong y_{N}{ }^{(k)}\left(t_{i}\right)=\mathbf{P}\left(t_{i}\right) \boldsymbol{\Pi}^{k} \mathbf{A} ; i=0,1, \ldots, N$ or $\mathbf{Y}^{(k)}=\mathbf{P} \boldsymbol{\Pi}^{k} \mathbf{A}$

Thus, the nonlinear part of Eq. (9) can be written as 
$\sum_{p=0}^{2} \sum_{\boldsymbol{q}=0}^{p} \boldsymbol{Q}_{p \boldsymbol{q}} \boldsymbol{Y}^{(p, \boldsymbol{q})}=\boldsymbol{Q}_{00} \boldsymbol{Y}^{(0,0)}+\boldsymbol{Q}_{10} \boldsymbol{Y}^{(1,0)}+\boldsymbol{Q}_{11} \boldsymbol{Y}^{(1,1)}+\boldsymbol{Q}_{20} \boldsymbol{Y}^{(2,0)}+\boldsymbol{Q}_{21} \boldsymbol{Y}^{(2,1)}+\boldsymbol{Q}_{22} \boldsymbol{Y}^{(2,2)}$

Substituting the collocation points (8) into the mentioned matrix relations, then the following matrices are obtained:

$\mathbf{Y}^{(0,0)}=\mathbf{P}_{0,0}^{*} \overline{\mathbf{A}}, \quad \mathbf{Y}^{(1,0)}=\mathbf{P}_{1,0}^{*} \overline{\mathbf{A}}, \quad \mathbf{Y}^{(1,1)}=\mathbf{P}_{1,1}^{*} \overline{\mathbf{A}}, \quad \mathbf{Y}^{(2,0)}=\mathbf{P}_{2,0}^{*} \overline{\mathbf{A}}, \quad \mathbf{Y}^{(2,1)}=\mathbf{P}_{2,1}^{*} \overline{\mathbf{A}}, \quad \mathbf{Y}^{(2,2)}=\mathbf{P}_{2,2}^{*} \overline{\mathbf{A}}$

where

$\mathbf{P}_{0,0}^{*}=\left[\begin{array}{c}P\left(t_{0}\right) \bar{P}\left(t_{0}\right) \\ P\left(t_{1}\right) \bar{P}\left(t_{1}\right) \\ \vdots \\ P\left(t_{N}\right) \bar{P}\left(t_{N}\right)\end{array}\right], \quad \mathbf{P}_{1,0}^{*}=\left[\begin{array}{c}P\left(t_{0}\right) \Pi \bar{P}\left(t_{0}\right) \\ P\left(t_{1}\right) \Pi \bar{P}\left(t_{1}\right) \\ \vdots \\ P\left(t_{N}\right) \Pi \bar{P}\left(t_{N}\right)\end{array}\right], \quad \mathbf{P}_{1,1}^{*}=\left[\begin{array}{c}P\left(t_{0}\right) \Pi \bar{P}\left(t_{0}\right) \bar{\Pi} \\ P\left(t_{1}\right) \Pi \bar{P}\left(t_{1}\right) \bar{\Pi} \\ \vdots \\ P\left(t_{N}\right) \Pi \bar{P}\left(t_{N}\right) \bar{\Pi}\end{array}\right], \quad \mathbf{P}_{2,0}^{*}=\left[\begin{array}{c}P\left(t_{0}\right) \Pi^{2} \bar{P}\left(t_{0}\right) \\ P\left(t_{1}\right) \Pi^{2} \bar{P}\left(t_{1}\right) \\ \vdots \\ P\left(t_{N}\right) \Pi^{2} \bar{P}\left(t_{N}\right)\end{array}\right]$

$\mathbf{P}_{2,1}^{*}=\left[\begin{array}{c}P\left(t_{0}\right) \Pi^{2} \bar{P}\left(t_{0}\right) \bar{\Pi} \\ P\left(t_{1}\right) \Pi^{2} \bar{P}\left(t_{1}\right) \bar{\Pi} \\ \vdots \\ P\left(t_{N}\right) \Pi^{2} \bar{P}\left(t_{N}\right) \bar{\Pi}\end{array}\right], \mathbf{P}_{2,2}^{*}=\left[\begin{array}{c}P\left(t_{0}\right) \Pi^{2} \bar{P}\left(t_{0}\right) \bar{\Pi}^{2} \\ P\left(t_{1}\right) \Pi^{2} \bar{P}\left(t_{1}\right) \bar{\Pi}^{2} \\ \vdots \\ P\left(t_{N}\right) \Pi^{2} \bar{P}\left(t_{N}\right) \bar{\Pi}^{2}\end{array}\right]$

\subsection{Legendre Operational Matrix Method}

Substituting the matrix relations (10) and (11) into Eq. (9), we obtain the fundamental matrix equation

$\sum_{k=0}^{m} \mathbf{F}_{k} \mathbf{P \Pi}^{k} \mathbf{A}+\sum_{p=0}^{2} \sum_{q=0}^{p} \mathbf{Q}_{p q} \mathbf{P}_{p, q}{ }^{*} \overline{\mathbf{A}}=\mathbf{G}$ or $\mathbf{W A}+\mathbf{V} \overline{\mathbf{A}}=\mathbf{G}$

where $\mathbf{W}=\left[w_{i j}\right]=\sum_{k=0}^{m} \mathbf{F}_{k} \mathbf{P \Pi}^{k} ; i, j=0,1, \ldots, N$ and

$\mathbf{V}=\left[v_{m^{*},(n+1)^{2}}\right]=\sum_{p=0}^{2} \sum_{q=0}^{p} \mathbf{Q}_{p q} \mathbf{P}_{p, q}^{*} ; m^{*}=0,1, \ldots, N ; n=0,1, \ldots,(N+1)^{2}-1$

Then, the matrix equation (12) can be written in the augmented form $[\mathbf{W} ; \mathbf{V}: \mathbf{G}]$ or clearly

$[\mathbf{W} ; \mathbf{V}: \mathbf{G}]=\left[\begin{array}{ccccccccccc}W_{00} & W_{01} & \ldots & W_{0 N} & : & V_{00} & V_{01} & \ldots & V_{0,(N+1)^{2}-1} & : & g\left(t_{0}\right) \\ W_{10} & W_{11} & \ldots & W_{1 N} & : & V_{10} & V_{11} & \ldots & V_{1,(N+1)^{2}-1} & \vdots & g\left(t_{1}\right) \\ \vdots & \vdots & \ddots & \vdots & \vdots & \vdots & \vdots & \ddots & \vdots & \vdots & \vdots \\ W_{N 0} & W_{N 1} & \ldots & W_{N N} & : & V_{N 0} & V_{N 1} & \ldots & V_{N,(N+1)^{2}-1} & : & g\left(t_{N}\right)\end{array}\right]$

Using the matrix relation (6), the fundamental matrix equation corresponding to the mixed conditions (2) is obtained as

$$
\sum_{k=0}^{m-1}\left(a_{k j} \mathbf{P}(-1)+b_{k j} \mathbf{P}(0)+c_{k j} \mathbf{P}(1)\right) \mathbf{\Pi}^{k} \mathbf{A}=\lambda_{j} ; j=0,1, \ldots, N \text { or } \mathbf{U A}+\mathbf{O}^{*} \overline{\mathbf{A}}=\lambda=\left[\mathbf{U} ; \mathbf{O}^{*}: \lambda\right]
$$

(Here, zero matrix indicated with $0^{*}$ is a $(N+1) \times(N+1)^{2}$ matrix) or more clearly

$$
\left[\mathbf{U} ; \mathbf{0}^{*}: \lambda\right]=\left[\begin{array}{ccccccccccc}
u_{00} & u_{01} & \ldots & u_{0 N} & : & 0 & 0 & \ldots & 0 & : & \lambda_{0} \\
u_{10} & u_{11} & \ldots & u_{1 N} & : & 0 & 0 & \ldots & 0 & : & \lambda_{1} \\
\vdots & \vdots & \ddots & \vdots & : & \vdots & \vdots & \ddots & \vdots & : & \vdots \\
u_{N 0} & u_{N 1} & \ldots & u_{N N} & : & 0 & 0 & \ldots & 0 & : & \lambda_{m-1}
\end{array}\right]
$$


To calculate Legendre coefficients $a_{n}(n=0,1, \ldots, N)$ related to the approximate solution (3) of the problem (1)-(2), by replacing the $m$ row matrices (14) by the last $m$ rows (or any $m$ rows) of the augmented matrix (16), we obtain the resulting matrix as follows;

$$
[\tilde{\mathbf{W}} ; \tilde{\mathbf{V}}: \tilde{\mathbf{G}}]=\left[\begin{array}{ccccccccccc}
W_{00} & W_{01} & \ldots & W_{0 N} & : & V_{00} & V_{01} & \ldots & V_{0,(N+1)^{2}-1} & : & g\left(t_{0}\right) \\
W_{10} & W_{11} & \ldots & W_{1 N} & : & V_{10} & V_{11} & \ldots & V_{1,(N+1)^{2}-1} & : & g\left(t_{1}\right) \\
\vdots & \vdots & \ddots & \vdots & \vdots & \vdots & \vdots & \ddots & \vdots & \vdots & \vdots \\
W_{N-m, 0} & W_{N-m, 1} & \ldots & W_{N-m, N} & \vdots & V_{N-m, 0} & V_{N-m, 1} & \ldots & V_{N-m,(N+1)^{2}-1} & : & g\left(t_{N-m}\right) \\
U_{00} & \vdots & \ldots & \vdots & \vdots & 0 & 0 & \ldots & 0 & \vdots & \lambda_{0} \\
U_{10} & \vdots & \ldots & \vdots & \vdots & 0 & 0 & \ldots & 0 & \vdots & \lambda_{1} \\
\vdots & \vdots & \ddots & \vdots & \vdots & \vdots & \vdots & \ddots & \vdots & \vdots & \vdots \\
U_{m-1,0} & U_{m-1,1} & \ldots & U_{m-1, N} & : & 0 & 0 & \ldots & 0 & \vdots & \lambda_{m-1}
\end{array}\right]
$$

From this nonlinear algebraic system, that is, from the matrix equation $\tilde{\mathbf{W}} \mathrm{A}+\tilde{\mathbf{V}}(\overline{\mathbf{A}})=\tilde{\mathbf{G}}$, the unknown Legendre coefficients $a_{n}(n=0,1, \ldots, N)$ are determined. Thus, the truncated Legendre series solution (3) is obtained from Eqs. (4) and (7).

\section{Accuracy of Solutions and Residual Error Estimation}

We consider the residual error estimation to check accuracy of the obtained solutions. Since the truncated Legendre series (1) is an approximate solution of Eq. (1), when the solution $y_{N}(x)$ and its derivatives are substituted in Eq. (1), then resulting equation must be satisfied approximately as follows:

$R_{N}\left(t_{l}\right)=\sum_{k=0}^{m} F_{k}\left(t_{l}\right) y^{(k)}\left(t_{l}\right)+\sum_{p=0}^{2} \sum_{q=0}^{p} Q_{p q}\left(t_{l}\right) y^{(p)}\left(t_{l}\right) y^{(q)}\left(t_{l}\right)-g\left(t_{l}\right) \cong 0$

for $t_{l} \in[a, b](l=0,1,2, \ldots)$ or $R_{N}\left(t_{l}\right) \leq 10^{-k_{l}}$ where $k_{l}$ is any positive numbers. Predetermining $\max 10^{-k_{l}}=10^{-k}$, then the truncation limit $N$ is increased until the difference $R_{N}\left(t_{l}\right)$ at each of the points becomes smaller than predetermined $10^{-k}$. Therefore, if $R_{N}\left(t_{l}\right) \rightarrow 0$ when $N$ is sufficiently large enough, then the error decreases (Everitt et.al. 2002; Sezer and Gülsu, 2010).

The accuracy of the solution can be checked and the error can be estimated via the residual function $R_{N}(t)$ (Balc1 and Sezer, 2016; Oğuz and Sezer, 2015, Kürkçü et. al., 2016, Gürbüz and Sezer, 2017) and the mean value of the function $\left|R_{N}(t)\right|$ on the interval $[-1,1]$. Using the inequality

$\left|\int_{-1}^{1} R_{N}(t) d t\right| \leq \int_{-1}^{1}\left|R_{N}(t)\right| d t$

and the mean value theorem, the upper bound of the mean error $\bar{R}_{n}$ is obtained as

$$
R_{N}(c) \leq \frac{1}{2} \int_{-1}^{1}\left|R_{N}(t)\right| d t=\bar{R}_{N}
$$

\section{Applications}

Example 4.1. Consider the nonlinear differential equation

$y^{\prime \prime}-2 y^{\prime}+y+y^{2}-y^{\prime \prime} y^{\prime}=2+4 e^{t} ; \quad y(0)=3, \quad y^{\prime}(0)=2$

We assume that the problem has a Legendre polynomial solution in the form for $N=2$ 
$y_{2}(t)=\sum_{n=0}^{2} a_{n} P_{n}(t) ; \quad-1 \leq t \leq 1$

Performing the necessary procedures and considering the collocation points $P_{0}(t)=1, P_{1}(t)=t, P_{2}(t)=\frac{3}{2} t^{2}-\frac{1}{2}$, then, we find the fundamental matrix equation in the following:

$$
\left(\boldsymbol{F}_{0} \boldsymbol{P} \boldsymbol{\Pi}^{0}+\boldsymbol{F}_{1} \boldsymbol{P} \boldsymbol{\Pi}+\boldsymbol{F}_{2} \boldsymbol{P} \boldsymbol{\Pi}^{2}\right) \boldsymbol{A}+\left(\boldsymbol{Q}_{00} \boldsymbol{P}_{0,0}^{*}+\boldsymbol{Q}_{21} \boldsymbol{P}_{2,1}^{*}\right) \overline{\dot{\boldsymbol{A}}}=\boldsymbol{G}
$$

where

$\boldsymbol{F}_{0} \boldsymbol{P} \boldsymbol{\Pi}^{0}=\left[\begin{array}{ccc}1 & -1 & 1 \\ 1 & 0 & -1 / 2 \\ 0 & 0 & 1\end{array}\right], \boldsymbol{F}_{1} \boldsymbol{P} \boldsymbol{\Pi}=\left[\begin{array}{ccc}0 & -2 & 6 \\ 0 & -2 & 0 \\ 0 & -2 & -6\end{array}\right], \boldsymbol{F}_{2} \boldsymbol{P} \boldsymbol{\Pi}^{2}=\left[\begin{array}{lll}0 & 0 & 3 \\ 0 & 0 & 3 \\ 0 & 0 & 3\end{array}\right], \mathbf{G}=\left[\begin{array}{c}g(-1) \\ g(0) \\ g(1)\end{array}\right]=\left[\begin{array}{c}2+4 e^{-1} \\ 6 \\ 2+4 e\end{array}\right]$

$\mathbf{Q}_{00} \mathbf{P}^{*}{ }_{0,0}+\mathbf{Q}_{21} \mathbf{P}_{2,1}^{*}=\left[\begin{array}{ccccccccc}1 & -1 & 1 & 1 & -1 & 1 & -2 & 2 & -2 \\ 1 & 0 & -1 / 2 & 0 & 0 & 0 & 1 / 2 & -3 & 1 / 4 \\ 1 & 1 & 1 & 1 & 1 & 1 & 1 & -2 & -8\end{array}\right]$

$[\boldsymbol{W} ; \tilde{\boldsymbol{V}}: \tilde{\boldsymbol{G}}]=\left[\begin{array}{ccccccccccccccc}1 & -3 & 10 & : & 1 & -1 & 1 & 1 & -1 & 1 & -2 & 2 & -2 & : & 2+4 \boldsymbol{e}^{-1} \\ 1 & 0 & -1 / 2 & : & 0 & 0 & 0 & 0 & 0 & 0 & 0 & 0 & 0 & : & 3 \\ 0 & 1 & 0 & : & 0 & 0 & 0 & 0 & 0 & 0 & 0 & 0 & 0 & : & 2\end{array}\right]$

Then, the solution of the problem is obtained as the first three term in Maclaurin expansion of the exact solution $y=1+2 e^{t}$.

Table 1. Numerical results for Example 4.1.

\begin{tabular}{|c|c|c|c|}
\hline$t_{i}$ & $\begin{array}{l}\text { Exact } \\
\text { Solution }\end{array}$ & $y(t)$ for $N=2$ & $\begin{array}{l}\text { Absolute } \\
\text { Errors }\end{array}$ \\
\hline 0.0 & 3.0 & 3.0 & 0 \\
\hline 0.2 & 3.4428 & 3.44 & 0.0028 \\
\hline 0.4 & 3.9836 & 3.96 & 0.2364 \\
\hline 0.6 & 4.6442 & 4.56 & 0.8423 \\
\hline 0.8 & 5.4510 & 5.24 & 0.2110 \\
\hline 1.0 & 6.4365 & 6.0 & 0.4365 \\
\hline
\end{tabular}




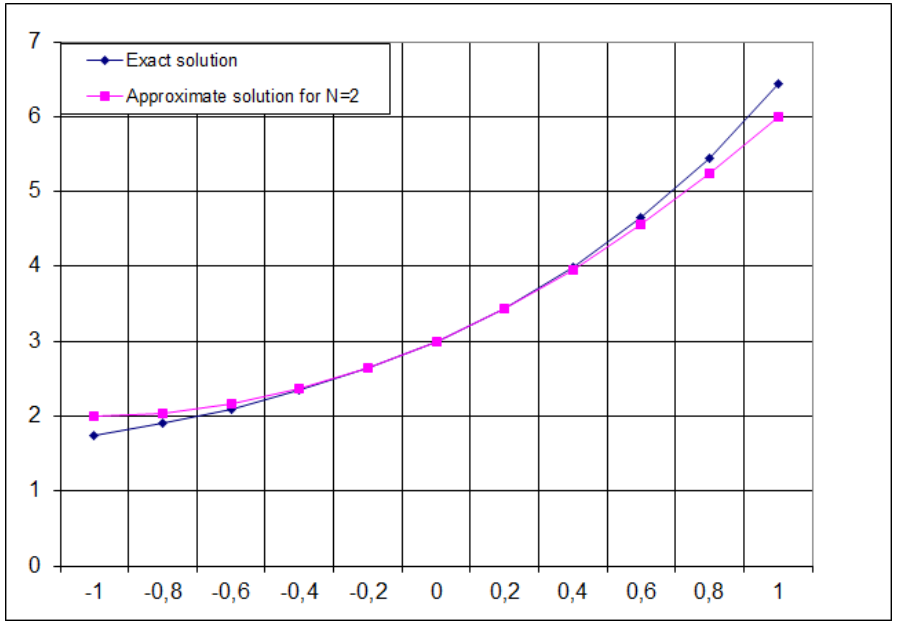

Figure 1. The comparison of numerical and exact solutions of Example 4.1 for $N=2$.

Example 4.2. $[9,13]$ Consider Bratu-type problem

$$
y^{\prime \prime}(x)-2 e^{y(x)}=0 ; 0<x<1
$$

with $y(0)=0$ and $y^{\prime}(0)=0$. The exact solution of this problem is $y(x)=-2 \ln (\cos x)$. Expanding $e^{y(x)}$, we can write this equation [9] as

$$
y^{\prime \prime}(x)-2 y(x)-y^{2}(x)-2=0 .
$$

Using Legendre matrix-collocation method with truncation limit $N=4$ and 5, we solve this problem. The following solutions are obtained as

$$
\begin{gathered}
y_{4}(x)=-1.04 \times 10^{-17}+0.965317 x^{2}-0.0160093 x^{3}+0.196559 x^{4} \\
y_{5}(x)=2.08 \times 10^{-17}+0.971444 x^{2}+0.00924656 x^{3}+0.146425 x^{4}+0.0314368 x^{5}
\end{gathered}
$$

Table 2. Comparison of the absolute errors for different $N$ of Example 4.2.

\begin{tabular}{|c|l|l|c|l|c|}
\hline$x_{i}$ & $\mathrm{~N}=4$ & $\mathrm{~N}=5$ & $x_{i}$ & $\mathrm{~N}=4$ & $\mathrm{~N}=5$ \\
\hline 0.1 & $3.60 e-04$ & $2.78 e-04$ & 0.6 & $1.44 e-02$ & $1.08 e-02$ \\
\hline 0.2 & $1.47 e-03$ & $1.09 e-03$ & 0.7 & $2.15 e-02$ & $1.66 e-02$ \\
\hline 0.3 & $3.34 e-03$ & $2.44 e-03$ & 0.8 & $3.27 e-02$ & $2.60 e-02$ \\
\hline 0.4 & $6.00 e-03$ & $4.36 e-03$ & 0.9 & $5.17 e-02$ & $4.26 e-02$ \\
\hline 0.5 & $9.56 e-03$ & $7.02 e-03$ & - & - & - \\
\hline
\end{tabular}

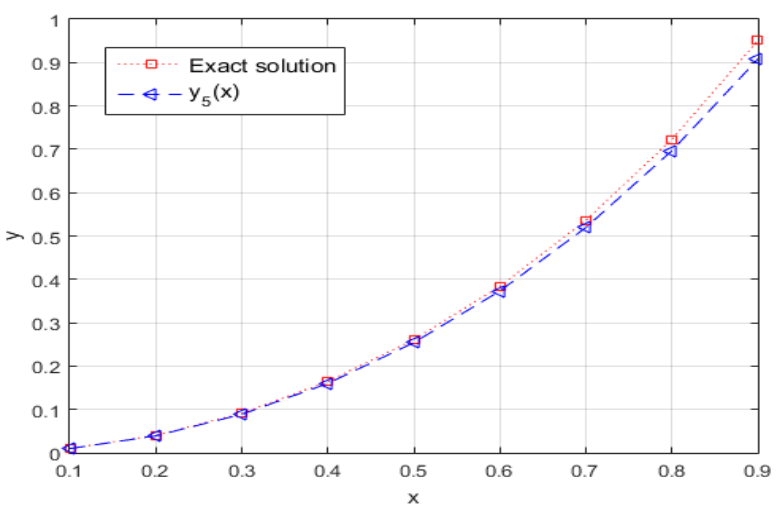

Figure 2. Comparison of the Legendre polynomial solution $y_{5}(x)$ and exact solution for Example 4.2. 
As seen from Fig. 2 and Table 2, the Legendre polynomial solutions $y_{4}(x)$ and $y_{5}(x)$ coincide with the exact solution. Also, the absolute error decreases as $N$ is increased. The upper bounds of the mean errors $\bar{R}_{4}$ and $\bar{R}_{5}$ are obtained as $2.07 e-01$ and $1.82 e-01$, respectively. It is clearly seen that the mean errors are consistent with results in tables and figures.

\section{Conclusions and Recommendations}

In this study, we propose a matrix-collocation method based on Legendre polynomials to obtain the approximate solutions of nonlinear ordinary differential equations with quadratic terms. Besides, the error analysis is introduced to indicate the accuracy of the method. The present method and its error analysis are applied on some examples. Comparison of the obtained results with exact solutions displays that the present method is impressive and suitable. Also, the method can be extended on different type of mathematical models together with some modifications.

\section{Acknowledge}

Competing interests: The authors declare that they have no competing interests.

Authors' contributions: All authors read and approved the final manuscript.

\section{References}

Akyüz Daşcıoğlu A., Çerdik Yaslan H. 2011. The solution of high-order nonlinear ordinary differential equations by Chebyshev series. Appl. Math. and Comput. 217, 5658-5666.

Balcı M. A., Sezer M. 2016. Hybrid Euler-Taylor matrix method for solving of generalized linear fredholm integro-differential difference equations. Appl. Math. Comput. 273, 33-41.

El-Mikkawy M.E.A., Cheon G.S. 2005. Combinatorial and hypergeometric identities via the Legendre polynomials-a computational approach. Appl. Math. Comput. 166, 181-195.

Everitt W.N., Littlejohn R., Wellman L.L. 2002. Legendre polynomials, Legendre-Stirling numbers and the left-definite spectral analysis of the Legendre differential expressions. J. Comput. Appl. Math. 148, 213-238.

Gülsu M., Sezer M., Tanay B. 2009. A matrix method for solving high-order linear difference equations with mixed argument using hybrid Legendre and Taylor polynomials. Journal of the Franklin Institute 343, 647-659.

Gürbüz B., Sezer M. 2016. Laguerre polynomial solutions of a class of initial and boundary value problems arising in science and engineering fields. Acta. Physica Polonica A 130 (1), 194-197.

Gürbüz B., Sezer, M. 2017. A new computational method based on Laguerre polynomials for solving certain nonlinear partial integro differential equations. Acta Physica Polonica A 132, 561-563.

Gürbüz B., Sezer, M. 2017. Laguerre polynomial solutions of a class of delay partial functional differential equations, Acta Physica Polonica A 132, 558-560.

Kreyszig E. 2013. Introductory functional analysis with applications, John-Wiley and Sons, New York.

Kürkçü Ö. K., Aslan E., Sezer M. 2017. A numerical method for solving some model problems arising in science and convergence analysis based on residual function. Appl. Num. Math. 121, 134-148.

Kürkçü Ö. K., Aslan E., Sezer M. 2016. A numerical approach with error estimation to solve general integro-differential difference equations using Dickson polynomials. Appl. Math. Comput. 276, 324-339.

Oğuz C., Sezer M. 2015. Chelyshkov collocation method for a class of mixed functional integro-differential equations. Appl. Math. Comput. 259, 943-954.

Sezer M., Gülsu M. 2010. Solving high-order linear differential equations by a Legendre matrix method based on hybrid Legendre and Taylor polynomials. Numer. Methods Partial Differential Eq. 26, 647-661.

Wazwaz A. M. 2005. Adomian decomposition method for a reliable treatment of the Bratu-type equations. Appl. Math. Comput. 166, 652-663.

Yüksel G., Gülsu M., Sezer M. 2011. Chebyshev polynomial solutions of a class of second-order nonlinear ordinary differential equations. Journal of Advanced Research in Scientific Computing 3(4), 11-24. 